\title{
Hypoxia-Inducible Factor (HIF) as a Target for Novel Therapies in Rheumatoid Arthritis
}

\author{
Susan Hua ${ }^{1,2 *}$ and Thilani H. Dias ${ }^{1}$ \\ ${ }^{1}$ School of Biomedical Sciences and Pharmacy, University of Newcastle, Callaghan, NSW, Australia, ${ }^{2}$ Hunter Medical \\ Research Institute, New Lambton Heights, NSW, Australia
}

Hypoxia is an important micro-environmental characteristic of rheumatoid arthritis (RA). Hypoxia-inducible factors (HIF) are key transcriptional factors that are highly expressed in RA synovium to regulate the adaptive responses to this hypoxic milieu. Accumulating evidence supports hypoxia and HIFs in regulating a number of important pathophysiological characteristics of RA, including synovial inflammation, angiogenesis, and cartilage destruction. Experimental and clinical data have confirmed the upregulation of both HIF-1 $\alpha$ and HIF-2 $\alpha$ in RA. This review will focus on the differential expression

OPEN ACCESS

Edited by:

Annalisa Bruno,

Università degli Studi "G. d'Annunzio"

Chieti - Pescara, Italy

Reviewed by:

Aida Habib,

American University of Beirut,

Lebanon

Marina Korotkova,

Karolinska Institutet, Sweden

*Correspondence:

Susan Hua

susan.hua@newcastle.edu.au

Specialty section: This article was submitted to Inflammation Pharmacology, a section of the journal

Frontiers in Pharmacology

Received: 08 May 2016

Accepted: 10 June 2016

Published: 27 June 2016

Citation:

Hua S and Dias TH (2016) Hypoxia-Inducible Factor (HIF) as a

Target for Novel Therapies in Rheumatoid Arthritis.

Front. Pharmacol. 7:184. doi: 10.3389/fphar.2016.00184 of HIFs within the synovial joint and its functional behavior in different cell types to regulate RA progression. Potential development of new therapeutic strategies targeting HIF-regulated pathways at sites of disease in RA will also be addressed.

Keywords: rheumatoid arthritis, hypoxia, hypoxia-inducible factor, inflammation, synovitis, angiogenesis, cartilage degradation, targeted therapy

\section{INTRODUCTION}

Rheumatoid arthritis (RA) is the most common form of inflammatory arthritis. It is an autoimmune and polyarthritic condition, characterized by inflammation of the synovium (synovitis), progressive cartilage destruction, and bone erosion, which ultimately results in loss of integrity of the affected joints (Lautenbach et al., 2013). The RA synovium is enriched with a variety of cell types, including synovial fibroblasts, immune cells (e.g., mast cells, macrophages, neutrophils, dendritic cells, B cells, and T cells; Hitchon and El-Gabalawy, 2011), and newly formed blood vessels from the pre-existing vasculature (angiogenesis; Paleolog, 2002) (Figure 1). Hypoxia is an important micro-environmental characteristic of RA (Lund-Olesen, 1970; Hitchon and El-Gabalawy, 2004; Gaber et al., 2005; Konisti et al., 2012). This is mainly due to hyperplasia of the synovial lining and increased infiltration of immune cells, which together enhance the synovial demand for oxygen (Peters et al., 2004; Lee et al., 2007; Jeon et al., 2008). Induction of angiogenesis is likely a consequence of synovial hypoxia in RA (Paleolog, 2002). However, this increased neovascularization, primarily of dysregulated and immature blood vessels, is unable to provide adequate oxygen perfusion to balance the increased demand (Distler et al., 2004; Taylor and Sivakumar, 2005; Kennedy et al., 2010). Analysis of the oxygen tension $\left(\mathrm{pO}_{2}\right)$ levels in the synovial fluid of knee joints in RA patients have consistently shown significantly lower levels (51.0 $\pm 16.5 \mathrm{mmHg})$ in comparison to patients with osteoarthritis $(79.2 \pm 14.0 \mathrm{mmHg})$, despite similar synovial thickness scores (Lee et al., 2007). This suggests that synovial proliferation may contribute more to hypoxia in the joint cavities of RA patients. 
In response to the alterations in oxygen tension, hypoxiainducible factors (HIFs) are activated as an adaptive mechanism. HIFs are considered the "master regulators" (Imtiyaz and Simon, 2010), and belong to the family of basic-helix-loop-helix/PerARNT-Sim (bHLH/PAS) DNA binding transcription factors (Greer et al., 2012). HIF-1 is a heterodimeric transcription factor, composed of two subunits-HIF- $1 \alpha$ and HIF- $1 \beta$. HIF- $1 \alpha$ is regulated by oxygen levels and post-translational modifications that are sensitive to oxygen levels, whereas HIF-1 $\beta$ is expressed constitutively in the nucleus (Konisti et al., 2012). Three HIF$\alpha$ isoforms have been identified to date (HIF-1 $\alpha$, HIF-2 $\alpha$ HIF$3 \alpha$ ), with HIF-1 $\alpha$ being the most widely investigated (Fan et al., 2014). Activation of the HIF pathway generally allows cells to survive in a hypoxic environment (Semenza, 1998; Harris, 2002), however in some cases these adaptive responses can accelerate disease progression (Ikeda, 2005). Increasing evidence suggest that HIFs play a major role in perpetuating the pathogenesis of RA (Figure 1). In particular, HIF- $1 \alpha$ can activate pathways that lead to synovitis, angiogenesis, cartilage degradation, and bone erosion (Konisti et al., 2012; Elshabrawy et al., 2015; Biniecka et al., 2016; Hu et al., 2016). Recent studies have begun to investigate the role of HIF- $2 \alpha$ in RA, with initial results demonstrating a potential role as a catabolic factor (Huber et al., 2006; Ryu et al., 2014; Huh et al., 2015). This review will focus on the differential expression of HIF within the synovial joint and its functional behavior in different cell types to regulate disease progression. Potential development of new therapeutic strategies targeting HIF-regulated pathways at sites of disease will also be addressed.

\section{HIF EXPRESSION WITHIN AFFECTED RA JOINTS}

HIFs are highly expressed in the hyperplastic RA synovium, which primarily consists of fibroblast-like synoviocytes (FLS) and macrophage-like synoviocytes (MLS; Hitchon et al., 2002). FLS are key effector cells in the pathogenesis of RA, and are crucial in initiating and driving RA together with inflammatory cells ( $\mathrm{Li}$ et al., 2013a). Studies have reported a patchy and generalized HIF expression throughout the synovial tissue in both the nucleus and cytoplasm (Giatromanolaki et al., 2003; Westra et al., 2010). The degree of expression of the various HIF- $\alpha$ isoforms is only beginning to be elucidated. HIF- $1 \alpha$ is reported to be strongly expressed in the intimal layer of the RA synovium, including in resident macrophages (Hollander et al., 2001; Ahn et al., 2008). It has also been detected in the sub-lining layer in lower amounts (Hollander et al., 2001). Conversely, others have found HIF-1 $\alpha$ expression to be sparse in the RA synovium and reported HIF- $2 \alpha$ as the predominant isoform expressed in human RA joints and in the collagen-induced arthritis (CIA) model (Ryu et al., 2014). In particular, HIF-2 $\alpha$ expression was mainly observed in FLS of the RA synovium (Ryu et al., 2014). Furthermore, HIF-1 $\alpha$ and HIF$2 \alpha$ have also been identified in resident and infiltrating immune cells (e.g., macrophages, T cell, and mast cells), chondrocytes, and osteoclasts (Westra et al., 2010; Hardy et al., 2014; Ryu et al., 2014). Understanding the expression of HIFs within the RA joint allows us to better understand the degree in which they are activated based on disease severity, as well as how they affect particular cell types to contribute to perpetuating the disease.

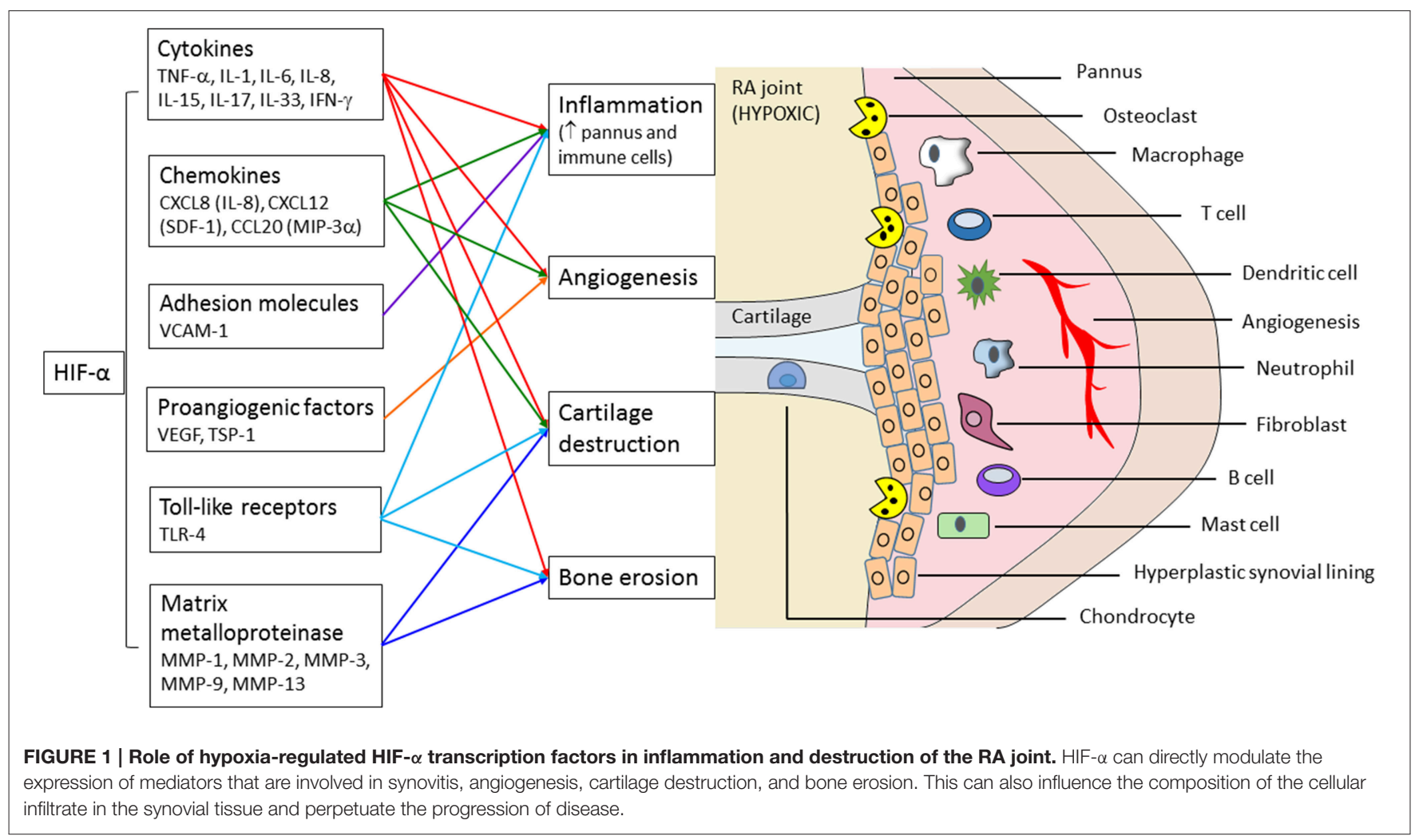




\section{HIF AND INFLAMMATION}

Synovitis is one of the major characteristics of RA. The synovium is a thin and soft tissue lining that consists of the intimal lining (intima) and an underlying loose connective tissue called the sub-lining (sub-intima) layer (Smith, 2011). The architecture of the synovium changes as the disease progresses, resulting in significant tissue edema and hyper-proliferation of the synovial cell lining to 10-15 layers (McInnes and Schett, 2011). The sub-intimal layer becomes heavily infiltrated with immune cells and undergoes neovascularization (McInnes and Schett, 2011). Increasing evidence suggest that HIF- $1 \alpha$ acts as a key regulator of inflammation in RA (Eltzschig and Carmeliet, 2011) (Figure 1). For example, PI3 kinase/Akt-mediated HIF-1 $\alpha$ expression has been shown to play a critical role in hypoxia-induced epithelialmesenchymal transition (EMT) phenotype transformation of FLS, synovial hyperplasia, and inflammatory cell infiltration in vivo in the CIA model (Li et al., 2013a). Conditional knockout of HIF- $1 \alpha$ in animal models of RA demonstrated clinical and histological improvement of experimental arthritis (Cramer et al., 2003). In particular, there was a significant reduction in synovial inflammation, pannus formation, and cartilage destruction in HIF-1 $\alpha$ knock-out mice (Cramer et al., 2003). Inhibition of HIF$1 \alpha$ signaling also attenuated hypoxia-induced invasiveness of activated FLS from the synovium of RA patients (Li et al., 2013b, 2015). Similarly, a recent study reported that HIF- $2 \alpha$ itself is capable of producing typical RA characteristics, with HIF- $2 \alpha$ deficient mice showing reduced development of experimental arthritis (Ryu et al., 2014).

Inflammatory factors are known to upregulate the expression HIF- $1 \alpha$ and HIF- $2 \alpha$ in RA. Pro-inflammatory cytokines such as IL-1, TNF- $\alpha$, and IL-33 have previously been reported to increase the expression of HIF isoforms in synovial fibroblasts (Thornton et al., 2000; Hu et al., 2013; Ryu et al., 2014) and in animal models of RA (Xu et al., 2008; Hu et al., 2013; Ryu et al., 2014). However, limited studies have investigated the direct effect of HIFs in upregulating pro-inflammatory cytokines in RA (Table 1). Recently, $\mathrm{Hu}$ et al. reported that HIF-1 $\alpha$ was able to directly potentiate the production of inflammatory cytokines (IL-6, IL-8, TNF- $\alpha$, and IL-1 $\beta$ ) and cell-cell contact mediators [IL-15, vascular cell adhesion molecule-1 (VCAM-1), thrombospondin-1 (TSP-1), and stromal cell-derived factor-1 (SDF-1/CXCL12)] in rheumatoid arthritis synovial fibroblasts (RASF; Hu et al., 2016). This was suggested to perpetuate RASF and T-cell/B-cell interactions, leading to RASF-mediated expansion of inflammatory Th1 and Th17 cells, as well as autoantibody production. In particular, knocking down HIF$1 \alpha$ in RASF inhibited IFN- $\gamma$, IL-17, and IgG production while enhancing protective natural IgM secretion by $\mathrm{T}$ cells and $\mathrm{B}$ cells (Hu et al., 2016). Co-expression of SDF-1 with HIF-1 $\alpha$ has been identified in both synovial tissue explants and synovial fibroblasts (Hitchon et al., 2002; Hu et al., 2016). SDF-1 is a chemokine that is upregulated in response to hypoxia in RA (Hitchon et al., 2002; Santiago et al., 2011), and is involved in a number of pathogenic events such as increased synovitis, angiogenesis, bone erosion, and cartilage destruction (Villalvilla et al., 2014). Upregulation of HIF-1 $\alpha$ has also been shown
TABLE 1 | Direct effects of HIF- $\alpha$ on cells in the RA joint.

\begin{tabular}{|c|c|c|}
\hline Cell type & Mediator & Source(s) \\
\hline \multirow{21}{*}{$\begin{array}{l}\text { Synovial } \\
\text { fibroblasts }\end{array}$} & $\uparrow I L-1 \beta$ & Hu et al., 2016 \\
\hline & $\uparrow \mathbb{I L}-6$ & Hu et al., 2016 \\
\hline & $\uparrow$ IL-8 (CXCL8) & $\begin{array}{l}\text { Ahn et al., 2008; Hu } \\
\text { et al., } 2016\end{array}$ \\
\hline & $\uparrow I L-15$ & Hu et al., 2016 \\
\hline & $\uparrow \mathrm{IL}-17$ & Hu et al., 2016 \\
\hline & $\uparrow I L-33$ & Hu et al., 2013, 2016 \\
\hline & $\uparrow T N F-\alpha$ & Hu et al., 2016 \\
\hline & $\uparrow$ TNF- $\alpha$ converting enzyme & $\begin{array}{l}\text { Charbonneau et al., } \\
2007\end{array}$ \\
\hline & $\uparrow$ IFN- $\gamma$ & Hu et al., 2016 \\
\hline & $\uparrow$ SDF-1 (CXCL12) & Hu et al., 2016 \\
\hline & $\uparrow \mathrm{MMP}-1$ & $\begin{array}{l}\text { Ahn et al., 2008; Lee } \\
\text { et al., } 2012\end{array}$ \\
\hline & $\uparrow \mathrm{MMP}-2$ & Li et al., 2013c \\
\hline & $\uparrow \mathrm{MMP}-3$ & Ahn et al., 2008 \\
\hline & $\uparrow$ MMP-9 & Li et al., 2013c \\
\hline & $\downarrow \mathrm{MMP}-13$ & Lee et al., 2012 \\
\hline & $\uparrow$ VEGF & $\begin{array}{l}\text { Akhavani et al., 2009; } \\
\text { Hu et al., } 2016\end{array}$ \\
\hline & $\uparrow$ EMT phenotype transformation & Li et al., 2013a \\
\hline & $\uparrow$ VCAM-1 & Hu et al., 2016 \\
\hline & $\uparrow \mathrm{TSP}-1$ & Hu et al., 2016 \\
\hline & $\uparrow \operatorname{lgG}$ production & Hu et al., 2016 \\
\hline & $\downarrow$ Protective natural lgM & Hu et al., 2016 \\
\hline \multirow[t]{5}{*}{ Myeloid cells } & $\uparrow$ TLR-4 & Kim et al., 2010 \\
\hline & $\uparrow$ VEGF & Fava et al., 1994 \\
\hline & $\uparrow$ CCL20 (MIP-3 $\alpha)$ & Bosco et al., 2008 \\
\hline & $\begin{array}{l}\text { Regulates glycolysis and energy } \\
\text { metabolism }\end{array}$ & Cramer et al., 2003 \\
\hline & $\begin{array}{l}\text { Protects THP-1 cells against } \\
\text { TLR-7/8-induced depletion of } \\
\text { ATP }\end{array}$ & $\begin{array}{l}\text { Nicholas and } \\
\text { Sumbayev, } 2009\end{array}$ \\
\hline Chondrocytes & $\begin{array}{l}\text { Essential in supporting } \\
\text { chondrocyte energy generation }\end{array}$ & $\begin{array}{l}\text { Otero and Goldring, } \\
2007\end{array}$ \\
\hline
\end{tabular}

to significantly enhances the expression of IL-33, which is then able to form a HIF-1 $\alpha /$ IL-33 regulatory circuit to further increase HIF-1 $\alpha$ expression (Hu et al., 2013). TNF- $\alpha$ converting enzyme, which is involved in regulating TNF- $\alpha$ levels, has also demonstrated to be HIF-1 $\alpha$ dependent in RA (Charbonneau et al., 2007). The effect of hypoxia and HIFs in regulating the expression of inflammatory factors is complex, as more than one pathway may be involved in inducing expression. For example, IL-6 expression was significantly increased in FLS under hypoxic conditions, however there are contradictory reports of the influence of HIF-1 $\alpha$ on its expression (Ahn et al., 2008; Hu et al., 2016).

Toll like receptors (TLR) are pattern recognition receptors that are mainly expressed in immune cells and RASF cells in RA to regulate inflammatory responses (Brentano et al., 2005; Ospelt et al., 2008; Huang and Pope, 2009; Hu et al., 
2014a). TLRs can be activated by a number of different factors present within the RA joint (Goh and Midwood, 2012; Xu et al., 2013; Lee et al., 2014). Limited data is available on the regulation of TLRs via hypoxia and HIFs in the pathogenesis of RA (Table 1). Kim et al. showed that hypoxia was able to upregulate the expression of TLR-4 in macrophages via a HIF$1 \alpha$ dependent pathway, leading to the activation of inflammatory mediators in macrophages (e.g., cyclooxygenase-2, IL-6, and RANTES; Kim et al., 2010). Furthermore, HIF-1 $\alpha$ may also help in the survival against TLR7/8-induced ATP depletion in THP-1 human myeloid macrophages (Nicholas and Sumbayev, 2009). Overexpression of HIF- $1 \alpha$ has been reported to enhance RASF-mediated expansion of inflammatory Th1 and Th17 cells, as well as enhance inflammatory cytokine expression in polyIC-stimulated RASF-thereby inducing a shift toward a proinflammatory state in RA (Hu et al., 2014b, 2016). This suggests that hypoxia and HIF-1 $\alpha$ may function in conjunction with TLRstimulated innate immune responses to drive inflammation in RA.

Immune cells also play an important role in synovial inflammation. HIF- $1 \alpha$ and HIF- $2 \alpha$ are highly expressed in immune cells, in particular macrophages, in the RA synovium (Hollander et al., 2001; Brouwer et al., 2009; Hardy et al., 2014). Resident macrophages (Type A synoviocytes) are primarily located in the intimal lining of the RA synovium, and are also found in the sub-lining layer and at the cartilage pannus junction (Kinne et al., 2000; Szekanecz and Koch, 2007). In response to hypoxia, macrophages upregulate HIFs to activate pathways involved in proliferation, angiogenesis, and glucose metabolism (Hollander et al., 2001; Brouwer et al., 2009; Hardy et al., 2014). Cramer et al. reported a significant reduction in synovitis, pannus formation, and disease progression with HIF$1 \alpha$ knockout myeloid cells in the $\mathrm{K} / \mathrm{BxN}$ serum transfer arthritis model (Cramer et al., 2003). Deletion of HIF-1 $\alpha$ in myeloid cells reduced disease severity in both acute and chronic inflammation. Similarly, macrophages lacking HIF- $2 \alpha$ significantly suppressed disease development in the $\mathrm{K} / \mathrm{BxN}$ serum transfer arthritis model, indicating an important role for HIF- $2 \alpha$ in supporting macrophages (Hardy et al., 2014).

\section{HIF AND ANGIOGENESIS}

Synovial angiogenesis is likely a consequence of synovial hypoxia in RA (Konisti et al., 2012; Azizi et al., 2014). The increased blood supply plays an important role in transporting immune cells to the site of inflammation and supplying nutrients to the pannus (Szekanecz and Koch, 2008). However, this dysregulated vasculature within the RA joint is unable to provide adequate oxygen supply (Taylor and Sivakumar, 2005; Kennedy et al., 2010) and promotes the generation of reactive oxygen species (ROS), which further enhances tissue damage within RA joints (Taylor and Sivakumar, 2005). HIFs have been suggested to regulate the expression of proangiogenic mediators, including vascular endothelial growth factor (VEGF; Fava et al., 1994; Koch et al., 1994), chemokine IL-8 (CXCL8; Ahn et al., 2008), CC-chemokine ligand 20 (CCL20; also known as macrophage inflammatory protein 3 $\alpha$, MIP-3 $\alpha$; Bosco et al., 2008), and SDF-1 (del Rey et al., 2009; Santiago et al., 2011; Table 1). VEGF is a key regulator of angiogenesis that is involved in proliferation, migration, vascular tube formation, and prevention of endothelial cell apoptosis (Elshabrawy et al., 2015). Both HIF$1 \alpha$ and HIF- $2 \alpha$ have been shown to increase the expression of VEGF in the inflammatory joint region, as well as in cells derived from RA synovium (Fava et al., 1994; Koch et al., 1994; Konisti et al., 2012). It should be noted that other pathways dependent or independent of HIF may also be involved in regulating the expression of proangiogenic factors. For example, the Notch signaling pathway has been shown to mediate hypoxia-induced angiogenesis in inflammatory arthritis via the interaction of Notch-1/HIF-1 through VEGF/Angiopoietin-2 (Gao et al., 2012) In addition, pro-inflammatory mediators are also able to promote RA angiogenesis, including cytokines [e.g., IL-17, IL-18, and macrophage migration inhibitory factor (MIF)], chemokines (CXCL12), growth factors (e.g., Ang1 and Ang2), proteases (MMPs), and adhesion molecules (e.g., ICAM-1 and VCAM-1; Elshabrawy et al., 2015).

\section{HIF AND CARTILAGE DESTRUCTION}

The articular cartilage is an avascular, aneural, and alymphatic tissue, which is composed primarily of chondrocytes. The role of HIFs in cartilage destruction in RA is not yet fully characterized, with the majority of the work conducted in healthy articular cartilage. Cells in the articular cartilage normally reside in a hypoxic environment, with oxygen tension varying from 6$10 \%$ at the joint surface to $1 \%$ in the deeper layers (Gibson et al., 2008). HIF-1 $\alpha$ acts as a survival factor in healthy cartilage (Schipani et al., 2001; Pfander et al., 2003; Mariani et al., 2014), and is essential in supporting chondrocyte energy generation (Pfander et al., 2003, 2005; Mobasheri et al., 2005; Mariani et al., 2014) and synthesis of the cartilage matrix (Pfander et al., 2005; Mariani et al., 2014). Similarly, HIF-2 $\alpha$ has been shown to have a major role in anabolic responses in healthy human chondrocytes (Lafont et al., 2007, 2008; Thoms et al., 2013; Zhang et al., 2015). Initial results suggest that HIF may be involved in perpetuating cartilage destruction in RA (Figure 1). As chronic inflammation advances in RA, the hyperplastic pannus aggressively invades and destroys the articular cartilage, particularly in the regions that are contiguous with the proliferating synovial pannus (Williams et al., 2000; Goldring, 2003; Otero and Goldring, 2007). The synovial pannus contains invasive RASF cells which are the main cells responsible for marginal cartilage destruction, via the production of cartilage degrading enzymes called matrix metalloproteinases (MMPs) (Abeles and Pillinger, 2006). Recent studies have shown that membrane-type MMPs (MT1-MMP and MT3-MMP) (Pap et al., 2000a,b) and cathepsin group of proteases (cathepsin B, cathepsin L, capthesin D and capthesin K) also contribute to cartilage destruction in RA (Pap et al., 2000b).

Hypoxia has been demonstrated to upregulate the levels of MMPs in cells derived from RA synovium, although additional pathways independent of HIF may also be involved (Canning et al., 2001; Ben-Yosef et al., 2002; Cha et al., 2003; Akhavani 
et al., 2009; Table 1). Lee et al. demonstrated an increase in MMP1 protein expression and a corresponding decrease in MMP13 protein expression in IL- $1 \beta$-stimulated FLS derived from RA synovium under hypoxic conditions (Lee et al., 2012). This differential effect of hypoxia on MMP production was shown to be HIF-1 $\alpha$-dependent. MMP-3 has also been shown to be directly controlled by the activation of HIF-1 $\alpha$ in FLS (Ahn et al., 2008). Interestingly, hypoxia-induced MMP-1 expression was not significantly attenuated by knock-down of HIF- $1 \alpha$, which suggests other pathways are also involved in the expression of MMPs (Ahn et al., 2008). Similarly, IL-17A was shown to induce MMP-2 and MMP-9 expression, via a HIF- $1 \alpha /$ NF-kB pathway (Li et al., 2013c). Although the majority of the initial studies have been conducted in vitro on cells derived from RA synovium, further ex vivo and in vivo studies are warranted to assist in strengthening our understanding of the complex role of HIF in cartilage degradation in RA.

\section{TARGETING HIF-REGULATED PATHWAYS IN RA}

Studies to date suggest that HIFs are promising targets for novel RA treatments. Approaches that may be considered for targeting hypoxia in RA cells include the use of hypoxia-activated prodrugs, specific HIF inhibitors, gene therapy, or targeting indirect pathways important in hypoxic cells. The majority of these targeted therapies have come from research on the effects of hypoxia on the growth of tumors (Phillips, 2016; Wigerup et al., 2016). Hypoxic prodrugs were designed to be selectively activated in hypoxic tissue, via reduction of the prodrug by cellular reductases, thereby delivering the active agent to hypoxic cells (Phillips, 2016). These therapeutic agents appear to use hypoxia as a targeting mechanism to deliver therapeutic agents to specific disease sites. The main issue is the risk of off-target effects due to the fact that hypoxia is a dynamic process that occurs physiologically as well as in a multitude of diseases.

A number of HIF inhibitors have been developed that possess inhibitory activity against cancer and HIF-related diseases (Ban et al., 2016). There are considerably fewer selective and specific HIF inhibitors compared to non-selective HIF inhibitors that can target multiple pathways. Initial clinical trials of these agents in various forms of cancer and other hypoxia-related diseases have shown encouraging results (Konisti et al., 2012; Wigerup et al., 2016). The majority of these compounds are still in the early stages of development and have yet to be assessed in clinical trials for RA (Manabe et al., 2008; del Rey et al., 2009; Shankar et al., 2009; Wigerup et al., 2016). Reasons for this include the complexity of the HIF pathway in RA and their different mechanisms of action for HIF inhibition, as well as pharmacokinetic and stability issues that prevent these therapeutic agents from reaching the target cells following administration (Ban et al., 2016; Wigerup et al., 2016). Local administration of these compounds (e.g., intraarticular injection) was proposed as an option to avoid any pharmacokinetic issues or premature systemic degradation.
However, this route of administration is not always preferable in conditions involving multiple sites and/or difficult to reach sites.

The use of delivery carriers may improve the efficacy of HIFrelated therapeutic agents following systemic administration, by overcoming the pharmacokinetic and stability issues. The best example of this is in the delivery of gene therapy targeting HIFs, which have previously been shown to modulate cellular responses in hypoxia-related diseases (Post et al., 2007; Tal et al., 2008; Wang et al., 2008; del Rey et al., 2009; Chen et al., 2016). The delivery of small interfering RNA (siRNA) remains a challenge because of the lack of suitable vectors. Transfection of fibroblasts with lentiviruses expressing HIF- $1 \alpha$ siRNA demonstrated significant reduction in HIF- $1 \alpha$ accumulation and VEGF mRNA levels in an in vivo model of RA (del Rey et al., 2009). Although viral vectors have shown to be effective, the concerns surrounding their safety have limited their application. Therefore, non-viral vectors have been investigated as an alternative delivery platform for HIF gene deliveryincluding liposomes (Wang et al., 2008; Chen et al., 2016) and polymer-based nanoparticles (Liu et al., 2009). For example, Wang et al. demonstrated that PEGylated liposomes loaded with doxorubicin and antisense oligonucleotides targeted to HIF-1 $\alpha$ mRNA was able to effectively deliver the active agents into tumor cells on nude mice bearing xenografts of multidrug-resistant human ovarian carcinoma (Wang et al., 2008). The proposed combination therapy increased the therapeutic efficacy of the chemotherapy to an extent that was not able to be achieved by administration of the individual components separately (Wang et al., 2008). These results demonstrate that packaging active agents targeting HIF-regulated pathways into delivery vehicles, which are designed to accumulate specifically at sites of RA disease, may improve therapeutic efficacy and reduce off-target effects (Sercombe et al., 2015).

Indirect strategies to target downstream HIF signaling pathways have also been investigated in RA. For example, many therapeutic approaches have successfully resolved angiogenesis in preclinical animal models of RA by administering antibodies targeting VEGF or small molecule inhibitors targeting the VEGF receptor (Maruotti et al., 2014). De Bandt et al. demonstrated that systemic administration of an anti-VEGF-RI monoclonal antibody $(\mathrm{mAb})$ in the $\mathrm{K} / \mathrm{BxN}$ mouse model of $\mathrm{RA}$ was able to delay the onset of arthritis, attenuate its intensity, and prevent joint destruction (De Bandt et al., 2003). Interestingly, $\mathrm{Lu}$ et al. reported that administration of anti-VEGF antibody before the onset of experimental arthritis was able to delay the onset and reduce the severity of disease in the CIA model, whereas administration post-onset of disease had no effect on the progression or severity of the arthritis (Lu et al., 2000). The study suggested that VEGF may have a crucial role predominantly in the early stage of arthritis development. Unfortunately, a number of these promising therapies have not yet been tested in clinical trials for RA. Those which have been tested in clinical trials were unable to translate the promising results in preclinical studies into successful treatment strategies for RA patients. This includes the discontinuation of phase II clinical trials studying MMP inhibitors in RA (Thabet and Huizinga, 2006; Dorman et al., 2010), as well as reduced efficacy of repeated 
administration of anti-ICAM-1 mAb in RA patients (Kavanaugh et al., 1996, 1997). This suggest that human RA is highly complex and heterogeneous, which involves multiple pathways occurring simultaneously to perpetuate disease (Elshabrawy et al., 2015).

\section{CONCLUSION}

Accumulating evidence supports hypoxia and HIFs in regulating a number of important pathophysiological characteristics of RA, including synovial inflammation, angiogenesis, and cartilage destruction. Therefore, HIF inhibitors are likely to target multiple important RA processes. Experimental and clinical data have confirmed the upregulation of both HIF- $1 \alpha$ and HIF- $2 \alpha$ in RA. At this time, the relative importance of each isoform in RA pathology and disease severity is still unclear. These two isoforms show different sensitivity to oxygen tension and display distinct, and sometimes opposing, cellular activities. In addition, further studies are required to clarify the interrelationship between HIFs and other simultaneous pathways in perpetuating RA disease. This will allow us to determine whether specific HIF- $1 \alpha$ or

\section{REFERENCES}

Abeles, A. M., and Pillinger, M. H. (2006). The role of the synovial fibroblast in rheumatoid arthritis: cartilage destruction and the regulation of matrix metalloproteinases. Bull. NYU Hosp. Jt. Dis. 64, 20-24.

Ahn, J. K., Koh, E. M., Cha, H. S., Lee, Y. S., Kim, J., Bae, E. K., et al. (2008). Role of hypoxia-inducible factor-1alpha in hypoxia-induced expressions of IL-8, MMP-1 and MMP-3 in rheumatoid fibroblast-like synoviocytes. Rheumatology (Oxford) 47, 834-839. doi: 10.1093/rheumatology/ken086

Akhavani, M. A., Madden, L., Buysschaert, I., Sivakumar, B., Kang, N., and Paleolog, E. M. (2009). Hypoxia upregulates angiogenesis and synovial cell migration in rheumatoid arthritis. Arthritis Res. Ther. 11, R64. doi: $10.1186 /$ ar2689

Azizi, G., Boghozian, R., and Mirshafiey, A. (2014). The potential role of angiogenic factors in rheumatoid arthritis. Int. J. Rheum. Dis. 17, 369-383. doi: 10.1111/1756-185X.12280

Ban, H. S., Uto, Y., Won, M., and Nakamura, H. (2016). Hypoxia-inducible factor (HIF) inhibitors: a patent survey (2011-2015). Expert Opin. Ther. Pat. 26, 309-322. doi: 10.1517/13543776.2016.1146252

Ben-Yosef, Y., Lahat, N., Shapiro, S., Bitterman, H., and Miller, A. (2002). Regulation of endothelial matrix metalloproteinase2 by hypoxia/reoxygenation. Circ. Res. 90, 784-791. doi: 10.1161/01.RES.0000015588.70132.DC

Biniecka, M., Canavan, M., McGarry, T., Gao, W., McCormick, J., Cregan, S., et al. (2016). Dysregulated bioenergetics: a key regulator of joint inflammation. Ann. Rheum. Dis. doi: 10.1136/annrheumdis-2015-208476. [Epub ahead of print].

Bosco, M. C., Delfino, S., Ferlito, F., Battaglia, F., Puppo, M., Gregorio, A., et al. (2008). Hypoxic synovial environment and expression of macrophage inflammatory protein 3gamma/CCL20 in juvenile idiopathic arthritis. Arthritis Rheum. 58, 1833-1838. doi: 10.1002/art.23516

Brentano, F., Kyburz, D., Schorr, O., Gay, R., and Gay, S. (2005). The role of Tolllike receptor signalling in the pathogenesis of arthritis. Cell. Immunol. 233, 90-96. doi: 10.1016/j.cellimm.2005.04.018

Brouwer, E., Gouw, A. S., Posthumus, M. D., van Leeuwen, M. A., Boerboom, A. L., Bijzet, J., et al. (2009). Hypoxia inducible factor-1-alpha (HIF-1alpha) is related to both angiogenesis and inflammation in rheumatoid arthritis. Clin. Exp. Rheumatol. 27, 945-951.

Canning, M. T., Postovit, L. M., Clarke, S. H., and Graham, C. H. (2001). Oxygen-mediated regulation of gelatinase and tissue inhibitor of metalloproteinases-1 expression by invasive cells. Exp. Cell Res. 267, 88-94. doi: $10.1006 /$ excr.2001.5243
HIF-2 $\alpha$ inhibition is likely to be required for successful clinical outcomes in RA. To optimize their effects, HIF inhibitors may require encapsulation within delivery vehicles directed toward affected RA tissue to improve therapeutic accumulation and stability following systemic administration, as well as reduce off-target effects.

\section{AUTHOR CONTRIBUTIONS}

SH was responsible for assembling, drafting and revising the manuscript, and preparing the associated figure and table. TD contributed to the drafting of this manuscript.

\section{ACKNOWLEDGMENTS}

This work was supported by The University of Newcastle, Hunter Medical Research Institute, The Pharmacy Research Trust of New South Wales, and The Rebecca L. Cooper Medical Research Foundation.

Cha, H. S., Ahn, K. S., Jeon, C. H., Kim, J., Song, Y. W., and Koh, E. M. (2003). Influence of hypoxia on the expression of matrix metalloproteinase-1, -3 and tissue inhibitor of metalloproteinase- 1 in rheumatoid synovial fibroblasts. Clin. Exp. Rheumatol. 21, 593-598.

Charbonneau, M., Harper, K., Grondin, F., Pelmus, M., McDonald, P. P., and Dubois, C. M. (2007). Hypoxia-inducible factor mediates hypoxic and tumor necrosis factor alpha-induced increases in tumor necrosis factor-alpha converting enzyme/ADAM17 expression by synovial cells. J. Biol. Chem. 282, 33714-33724. doi: 10.1074/jbc.M704041200

Chen, Z., Zhang, T., Wu, B., and Zhang, X. (2016). Insights into the therapeutic potential of hypoxia-inducible factor-1alpha small interfering RNA in malignant melanoma delivered via folate-decorated cationic liposomes. Int. J. Nanomed. 11, 991-1002. doi: 10.2147/IJN.S101872

Cramer, T., Yamanishi, Y., Clausen, B. E., Förster, I., Pawlinski, R., Mackman, N., et al. (2003). HIF- $1 \alpha$ is essential for myeloid cell-mediated inflammation. Cell 112, 645-657. doi: 10.1016/S0092-8674(03)00154-5

De Bandt, M., Ben Mahdi, M. H., Ollivier, V., Grossin, M., Dupuis, M., Gaudry, M., et al. (2003). Blockade of vascular endothelial growth factor receptor I (VEGF-RI), but not VEGF-RII, suppresses joint destruction in the $\mathrm{K} / \mathrm{BxN}$ model of rheumatoid arthritis. J. Immunol. 171, 4853-4859. doi: 10.4049/jimmunol.171.9.4853

del Rey, M. J., Izquierdo, E., Caja, S., Usategui, A., Santiago, B., Galindo, M., et al. (2009). Human inflammatory synovial fibroblasts induce enhanced myeloid cell recruitment and angiogenesis through a hypoxia-inducible transcription factor 1alpha/vascular endothelial growth factor-mediated pathway in immunodeficient mice. Arthritis Rheum. 60, 2926-2934. doi: $10.1002 /$ art. 24844

Distler, J. H., Wenger, R. H., Gassmann, M., Kurowska, M., Hirth, A., Gay, S., et al. (2004). Physiologic responses to hypoxia and implications for hypoxiainducible factors in the pathogenesis of rheumatoid arthritis. Arthritis Rheum. 50, 10-23. doi: 10.1002/art.11425

Dorman, G., Cseh, S., Hajdu, I., Barna, L., Konya, D., Kupai, K., et al. (2010). Matrix metalloproteinase inhibitors: a critical appraisal of design principles and proposed therapeutic utility. Drugs 70, 949-964. doi: 10.2165/11318390000000000-00000

Elshabrawy, H. A., Chen, Z., Volin, M. V., Ravella, S., Virupannavar, S., and Shahrara, S. (2015). The pathogenic role of angiogenesis in rheumatoid arthritis. Angiogenesis 18, 433-448. doi: 10.1007/s10456-0159477-2

Eltzschig, H. K., and Carmeliet, P. (2011). Hypoxia and inflammation. N. Engl. J. Med. 364, 656-665. doi: 10.1056/NEJMra0910283 
Fan, L., Li, J., Yu, Z., Dang, X., and Wang, K. (2014). The hypoxia-inducible factor pathway, prolyl hydroxylase domain protein inhibitors, and their roles in bone repair and regeneration. Biomed Res. Int. 2014:239356. doi: $10.1155 / 2014 / 239356$

Fava, R. A., Olsen, N. J., Spencer-Green, G., Yeo, K. T., Yeo, T. K., Berse, B., et al. (1994). Vascular permeability factor/endothelial growth factor (VPF/VEGF): accumulation and expression in human synovial fluids and rheumatoid synovial tissue. J. Exp. Med. 180, 341-346. doi: 10.1084/jem.180.1.341

Gaber, T., Dziurla, R., Tripmacher, R., Burmester, G. R., and Buttgereit, F. (2005). Hypoxia inducible factor (HIF) in rheumatology: low O2! See what HIF can do! Ann. Rheum. Dis. 64, 971-980. doi: 10.1136/ard.2004.031641

Gao, W., Sweeney, C., Connolly, M., Kennedy, A., Ng, C. T., McCormick, J., et al. (2012). Notch-1 mediates hypoxia-induced angiogenesis in rheumatoid arthritis. Arthritis Rheum. 64, 2104-2113. doi: 10.1002/art.34397

Giatromanolaki, A., Sivridis, E., Maltezos, E., Athanassou, N., Papazoglou, D., Gatter, K. C., et al. (2003). Upregulated hypoxia inducible factor-1 $\alpha$ and $2 \alpha$ pathway in rheumatoid arthritis and osteoarthritis. Arthritis Res. Ther. 5, R193-R201. doi: 10.1186/ar756

Gibson, J. S., Milner, P. I., White, R., Fairfax, T. P., and Wilkins, R. J. (2008). Oxygen and reactive oxygen species in articular cartilage: modulators of ionic homeostasis. Pflugers Arch. 455, 563-573. doi: 10.1007/s00424-007-0310-7

Goh, F. G., and Midwood, K. S. (2012). Intrinsic danger: activation of Tolllike receptors in rheumatoid arthritis. Rheumatology (Oxford) 51, 7-23. doi: 10.1093/rheumatology/ker257

Goldring, S. R. (2003). Pathogenesis of bone and cartilage destruction in rheumatoid arthritis. Rheumatology 42(Suppl. 2), iil1-iil6. doi: 10.1093/rheumatology/keg327

Greer, S. N., Metcalf, J. L., Wang, Y., and Ohh, M. (2012). The updated biology of hypoxia-inducible factor. $E M B O J .31,2448-2460$. doi: 10.1038/emboj.2012.125

Hardy, W., Wright, F., Hawtree, S., Fearon, U., Veale, D., Perretti, M., et al. (2014). Hypoxia-inducible factor 2a regulates macrophage function in rheumatoid arthritis. Ann. Rheum. Dis. 73, 174. doi: 10.1136/annrheumdis-2014-eular.4257

Harris, A. L. (2002). Hypoxia? A key regulatory factor in tumour growth. Nat. Rev. Cancer 2, 38. doi: 10.1038/nrc704

Hitchon, C., Wong, K., Ma, G., Reed, J., Lyttle, D., and El-Gabalawy, H. (2002). Hypoxia-induced production of stromal cell-derived factor 1 (CXCL12) and vascular endothelial growth factor by synovial fibroblasts. Arthritis Rheum. 46, 2587-2597. doi: 10.1002/art.10520

Hitchon, C. A., and El-Gabalawy, H. S. (2004). Oxidation in rheumatoid arthritis. Arthritis Res. Ther. 6, 265-278. doi: 10.1186/ar1447

Hitchon, C. A., and El-Gabalawy, H. S. (2011). The synovium in rheumatoid arthritis. Open Rheum. J. 5, 107-114. doi: 10.2174/1874312901105010107

Hollander, A. P., Corke, K. P., Freemont, A. J., and Lewis, C. E. (2001). Expression of hypoxia-inducible factor 1alpha by macrophages in the rheumatoid synovium: implications for targeting of therapeutic genes to the inflamed joint. Arthritis Rheum. 44, 1540-1544. doi: 10.1002/15290131(200107)44:7\&1t;1540::AID-ART277\&gt;3.0.CO;2-7

Hu, F., Liu, H., Xu, L., Li, Y., Liu, X., Shi, L., et al. (2016). Hypoxia-inducible factorlalpha perpetuates synovial fibroblast interactions with $\mathrm{T}$ cells and $\mathrm{B}$ cells in rheumatoid arthritis. Eur. J. Immunol. 46, 742-751. doi: 10.1002/eji.201545784

Hu, F., Li, Y., Zheng, L., Shi, L., Liu, H., Zhang, X., et al. (2014a). Toll-like receptors expressed by synovial fibroblasts perpetuate Th1 and Th17 cell responses in rheumatoid arthritis. PLoS ONE 9:e100266. doi: 10.1371/journal.pone.0100266

Hu, F., Mu, R., Zhu, J., Shi, L., Li, Y., Liu, X., et al. (2014b). Hypoxia and hypoxia-inducible factor- $1 \alpha$ provoke toll-like receptor signalling-induced inflammation in rheumatoid arthritis. Ann. Rheum. Dis. 73, 928-936. doi: 10.1136/annrheumdis-2012-202444

Hu, F., Shi, L., Mu, R., Zhu, J., Li, Y., Ma, X., et al. (2013). Hypoxiainducible factor- $1 \alpha$ and interleukin 33 Form a regulatory circuit to perpetuate the inflammation in rheumatoid arthritis. PLOS ONE 8:e72650. doi: 10.1371/journal.pone.0072650

Huang, Q. Q., and Pope, R. M. (2009). The role of toll-like receptors in rheumatoid arthritis. Curr. Rheumatol. Rep. 11, 357-364. doi: 10.1007/s11926-0090051-z

Huber, L. C., Distler, O., Tarner, I., Gay, R. E., Gay, S., and Pap, T. (2006). Synovial fibroblasts: key players in rheumatoid arthritis. Rheumatology (Oxford) 45, 669-675. doi: 10.1093/rheumatology/kel065
Huh, Y. H., Lee, G., Lee, K. B., Koh, J. T., Chun, J. S., and Ryu, J. H. (2015). HIF-2alpha-induced chemokines stimulate motility of fibroblastlike synoviocytes and chondrocytes into the cartilage-pannus interface in experimental rheumatoid arthritis mouse models. Arthritis Res. Ther. 17, 302. doi: 10.1186/s13075-015-0816-x

Ikeda, E. (2005). Cellular response to tissue hypoxia and its involvement in disease progression. Pathol. Int. 55, 603-610. doi: 10.1111/j.1440-1827.2005.01877.x

Imtiyaz, H. Z., and Simon, M. C. (2010). Hypoxia-inducible factors as essential regulators of inflammation. Curr. Top. Microbiol. Immunol. 345, 105-120. doi: 10.1007/82_2010_74

Jeon, C. H., Ahn, J. K., Chai, J. Y., Kim, H. J., Bae, E. K., Park, S. H., et al. (2008). Hypoxia appears at pre-arthritic stage and shows co-localization with early synovial inflammation in collagen induced arthritis. Clin. Exp. Rheumatol. 26, 646-648.

Kavanaugh, A. F., Davis, L. S., Jain, R. I., Nichols, L. A., Norris, S. H., and Lipsky, P. E. (1996). A phase I/II open label study of the safety and efficacy of an antiICAM-1 (intercellular adhesion molecule-1; CD54) monoclonal antibody in early rheumatoid arthritis. J. Rheumatol. 23, 1338-1344.

Kavanaugh, A. F., Schulze-Koops, H., Davis, L. S., and Lipsky, P. E. (1997). Repeat treatment of rheumatoid arthritis patients with a murine anti-intercellular adhesion molecule 1 monoclonal antibody. Arthritis Rheum. 40, 849-853. doi: 10.1002/art.1780400511

Kennedy, A., Chin Teck, N., Biniecka, M., Saber, T., Taylor, C., O'Sullivan, J., et al. (2010). Angiogenesis and blood vessel stability in inflammatory arthritis. Arthritis Rheum. 62, 711. doi: 10.1002/art.27287

Kim, S. Y., Choi, Y. J., Joung, S. M., Lee, B. H., Jung, Y. S., and Lee, J. Y. (2010). Hypoxic stress up-regulates the expression of Toll-like receptor 4 in macrophages via hypoxia-inducible factor. Immunology 129, 516-524. doi: 10.1111/j.1365-2567.2009.03203.x

Kinne, R. W., Bräuer, R., Stuhlmüller, B., Palombo-Kinne, E., and Burmester, G.R. (2000). Macrophages in rheumatoid arthritis. Arthritis Res. 2, 189-202. doi: $10.1186 /$ ar86

Koch, A. E., Harlow, L. A., Haines, G. K., Amento, E. P., Unemori, E. N., Wong, W. L., et al. (1994). Vascular endothelial growth factor. A cytokine modulating endothelial function in rheumatoid arthritis. J. Immunol. 152, 4149-4156.

Konisti, S., Kiriakidis, S., and Paleolog, E. M. (2012). Hypoxia-a key regulator of angiogenesis and inflammation in rheumatoid arthritis. Nat. Rev. Rheumatol. 8, 153-162. doi: 10.1038/nrrheum.2011.205

Lafont, J. E., Talma, S., Hopfgarten, C., and Murphy, C. L. (2008). Hypoxia promotes the differentiated human articular chondrocyte phenotype through SOX9-dependent and-independent pathways. J. Biol. Chem. 283, 4778-4786. doi: $10.1074 /$ jbc.M707729200

Lafont, J. E., Talma, S., and Murphy, C. L. (2007). Hypoxia-inducible factor 2alpha is essential for hypoxic induction of the human articular chondrocyte phenotype. Arthritis Rheum. 56, 3297-3306. doi: 10.1002/art.22878

Lautenbach, M., Millrose, M., Langner, I., and Eisenschenk, A. (2013). Results of Mannerfelt wrist arthrodesis for rheumatoid arthritis in relation to the position of the fused wrist. Int. Orthop. 37, 2409-2413. doi: 10.1007/s00264-013-2063-6

Lee, S. Y., Yoon, B. Y., Kim, J. I., Heo, Y. M., Woo, Y. J., Park, S. H., et al. (2014). Interleukin-17 increases the expression of Toll-like receptor 3 via the STAT3 pathway in rheumatoid arthritis fibroblast-like synoviocytes. Immunology 141, 353-361. doi: 10.1111/imm.12196

Lee, Y. A., Choi, H. M., Lee, S. H., Hong, S. J., Yang, H. I., Yoo, M. C., et al. (2012). Hypoxia differentially affects IL-1beta-stimulated MMP-1 and MMP-13 expression of fibroblast-like synoviocytes in an HIF-1alpha-dependent manner. Rheumatology (Oxford) 51, 443-450. doi: 10.1093/rheumatology/ker327

Lee, Y. A., Kim, J. Y., Hong, S. J., Lee, S. H., Yoo, M. C., Kim, K. S., et al. (2007). Synovial proliferation differentially affects hypoxia in the joint cavities of rheumatoid arthritis and osteoarthritis patients. Clin. Rheumatol. 26, 2023-2029. doi: 10.1007/s10067-007-0605-2

Li, G., Zhang, Y., Qian, Y., Zhang, H., Guo, S., Sunagawa, M., et al. (2013c). Interleukin-17A promotes rheumatoid arthritis synoviocytes migration and invasion under hypoxia by increasing MMP2 and MMP9 expression through NF-kappaB/HIF-1alpha pathway. Mol. Immunol. 53, 227-236. doi: 10.1016/j.molimm.2012.08.018

Li, G. F., Qin, Y. H., and Du, P. Q. (2015). Andrographolide inhibits the migration, invasion and matrix metalloproteinase expression of rheumatoid arthritis 
fibroblast-like synoviocytes via inhibition of HIF-1alpha signaling. Life Sci. 136, 67-72. doi: 10.1016/j.lfs.2015.06.019

Li, G. Q., Zhang, Y., Liu, D., Qian, Y. Y., Zhang, H., Guo, S. Y., et al. (2013a). PI3 kinase/Akt/HIF-1alpha pathway is associated with hypoxia-induced epithelialmesenchymal transition in fibroblast-like synoviocytes of rheumatoid arthritis. Mol. Cell. Biochem. 372, 221-231. doi: 10.1007/s11010-012-1463-Z

Li, G.-Q., Liu, D., Zhang, Y., Qian, Y.-Y., Zhu, Y.-D., Guo, S.-Y., et al. (2013b). Anti-invasive effects of celastrol in hypoxia-induced fibroblast-like synoviocyte through suppressing of HIF-1 $\alpha /$ CXCR 4 signaling pathway. Int. Immunopharmacol. 17, 1028-1036. doi: 10.1016/j.intimp.2013.10.006

Liu, Y., Tao, J., Li, Y., Yang, J., Yu, Y., Wang, M., et al. (2009). Targeting hypoxiainducible factor-1alpha with Tf-PEI-shRNA complex via transferrin receptormediated endocytosis inhibits melanoma growth. Mol. Ther. 17, 269-277. doi: $10.1038 / \mathrm{mt} .2008 .266$

Lu, J., Kasama, T., Kobayashi, K., Yoda, Y., Shiozawa, F., Hanyuda, M., et al. (2000). Vascular endothelial growth factor expression and regulation of murine collagen-induced arthritis. J. Immunol. 164, 5922-5927. doi: 10.4049/jimmunol.164.11.5922

Lund-Olesen, K. (1970). Oxygen tension in synovial fluids. Arthritis Rheum. 13, 769-776. doi: 10.1002/art.1780130606

Manabe, H., Nasu, Y., Komiyama, T., Furumatsu, T., Kitamura, A., Miyazawa, S., et al. (2008). Inhibition of histone deacetylase down-regulates the expression of hypoxia-induced vascular endothelial growth factor by rheumatoid synovial fibroblasts. Inflamm. Res. 57, 4-10. doi: 10.1007/s00011-007-7036-Z

Mariani, E., Pulsatelli, L., and Facchini, A. (2014). Signaling pathways in cartilage repair. Int. J. Mol. Sci. 15, 8667-8698. doi: 10.3390/ijms15058667

Maruotti, N., Cantatore, F. P., and Ribatti, D. (2014). Putative effects of potentially anti-angiogenic drugs in rheumatic diseases. Eur. J. Clin. Pharmacol. 70, 135-140. doi: 10.1007/s00228-013-1605-6

McInnes, I. B., and Schett, G. (2011). The pathogenesis of rheumatoid arthritis. N. Engl. J. Med. 365, 2205-2219. doi: 10.1056/NEJMra1004965

Mobasheri, A., Richardson, S., Mobasheri, R., Shakibaei, M., and Hoyland, J. A. (2005). Hypoxia inducible factor-1 and facilitative glucose transporters GLUT1 and GLUT3: putative molecular components of the oxygen and glucose sensing apparatus in articular chondrocytes. Histol. Histopathol. 20, 1327-1338.

Nicholas, S. A., and Sumbayev, V. V. (2009). The involvement of hypoxia-inducible factor 1 alpha in Toll-like receptor 7/8-mediated inflammatory response. Cell Res. 19, 973-983. doi: 10.1038/cr.2009.44

Ospelt, C., Brentano, F., Rengel, Y., Stanczyk, J., Kolling, C., Tak, P. P., et al. (2008). Overexpression of toll-like receptors 3 and 4 in synovial tissue from patients with early rheumatoid arthritis: toll-like receptor expression in early and longstanding arthritis. Arthritis Rheum. 58, 3684-3692. doi: 10.1002/art.24140

Otero, M., and Goldring, M. B. (2007). Cells of the synovium in rheumatoid arthritis. Chondrocytes. Arthritis Res. Ther. 9, 220. doi: 10.1186/ar2292

Paleolog, E. M. (2002). Angiogenesis in rheumatoid arthritis. Arthritis Res. 4(Suppl. 3), S81-S90. doi: 10.1186/ar575

Pap, T., Müller-Ladner, U., Gay, R. E., and Gay, S. (2000b). Fibroblast biology: role of synovial fibroblasts in the pathogenesis of rheumatoid arthritis. Arthritis Res. 2, 361-367. doi: 10.1186/ar113

Pap, T., Shigeyama, Y., Kuchen, S., Fernihough, J. K., Simmen, B., Gay, R. E., et al. (2000a). Differential expression pattern of membrane-type matrix metalloproteinases in rheumatoid arthritis. Arthritis Rheum. 43, 1226-1232. doi: 10.1002/1529-0131(200006)43:6\&lt;1226::AID-ANR5\&gt;3.0.CO;2-4

Peters, C. L., Morris, C. J., Mapp, P. I., Blake, D. R., Lewis, C. E., and Winrow, V. R. (2004). The transcription factors hypoxia-inducible factor lalpha and Ets1 colocalize in the hypoxic synovium of inflamed joints in adjuvant-induced arthritis. Arthritis Rheum. 50, 291-296. doi: 10.1002/art.11473

Pfander, D., Cramer, T., Schipani, E., and Johnson, R. S. (2003). HIF-1alpha controls extracellular matrix synthesis by epiphyseal chondrocytes. J. Cell Sci. 116(Pt 9), 1819-1826. doi: 10.1242/jcs.00385

Pfander, D., Cramer, T., and Swoboda, B. (2005). Hypoxia and HIF-1 $\alpha$ in osteoarthritis. Int. Orthop. 29, 6-9. doi: 10.1007/s00264-004-0618-2

Phillips, R. M. (2016). Targeting the hypoxic fraction of tumours using hypoxia-activated prodrugs. Cancer Chemother. Pharmacol. 77, 441-457. doi: 10.1007/s00280-015-2920-7

Post, D. E., Sandberg, E. M., Kyle, M. M., Devi, N. S., Brat, D. J., Xu, Z., et al. (2007). Targeted cancer gene therapy using a hypoxia inducible factor dependent oncolytic adenovirus armed with interleukin-4. Cancer Res. 67, 6872-6881. doi: 10.1158/0008-5472.CAN-06-3244

Ryu, J. H., Chae, C. S., Kwak, J. S., Oh, H., Shin, Y., Huh, Y. H., et al. (2014). Hypoxia-inducible factor-2alpha is an essential catabolic regulator of inflammatory rheumatoid arthritis. PLoS Biol. 12:e1001881. doi: 10.1371/journal.pbio.1001881

Santiago, B., Calonge, E., Del Rey, M. J., Gutierrez-Canas, I., Izquierdo, E., Usategui, A., et al. (2011). CXCL12 gene expression is upregulated by hypoxia and growth arrest but not by inflammatory cytokines in rheumatoid synovial fibroblasts. Cytokine 53, 184-190. doi: 10.1016/j.cyto.2010. 06.006

Schipani, E., Ryan, H. E., Didrickson, S., Kobayashi, T., Knight, M., and Johnson, R. S. (2001). Hypoxia in cartilage: HIF-1alpha is essential for chondrocyte growth arrest and survival. Genes Dev. 15, 2865-2876. doi: 10.1101/gad. 934301

Semenza, G. L. (1998). Hypoxia-inducible factor 1: master regulator of O2 homeostasis. Curr. Opin. Genet. Dev. 8, 588-594. doi: 10.1016/S0959437X(98)80016-6

Sercombe, L., Veerati, T., Moheimani, F., Wu, S. Y., Sood, A. K., and Hua, S. (2015). Advances and Challenges of Liposome Assisted Drug Delivery. Front. Pharmacol. 6:286. doi: 10.3389/fphar.2015.00286

Shankar, J., Thippegowda, P. B., and Kanum, S. A. (2009). Inhibition of HIF$1 \alpha$ activity by BP-1 ameliorates adjuvant induced arthritis in rats. Biochem. Biophys. Res. Commun. 387, 223-228. doi: 10.1016/j.bbrc.2009.01.086

Smith, M. D. (2011). The Normal Synovium. Open Rheumatol. J. 5, 100-106. doi: $10.2174 / 1874312901105010100$

Szekanecz, Z., and Koch, A. E. (2007). Macrophages and their products in rheumatoid arthritis. Curr. Opin. Rheumatol. 19, 289-295. doi: 10.1097/BOR.0b013e32805e87ae

Szekanecz, Z., and Koch, A. E. (2008). Vascular involvement in rheumatic diseases: 'vascular rheumatology'. Arthritis Res. Ther. 10, 224. doi: 10.1186/ar2515

Tal, R., Shaish, A., Rofe, K., Feige, E., Varda-Bloom, N., Afek, A., et al. (2008). Endothelial-targeted gene transfer of hypoxia-inducible factor-1alpha augments ischemic neovascularization following systemic administration. Mol. Ther. 16, 1927-1936. doi: 10.1038/mt.2008.191

Taylor, P. C., and Sivakumar, B. (2005). Hypoxia and angiogenesis in rheumatoid arthritis. Curr. Opin. Rheumatol. 17, 293-298. doi: 10.1097/01.bor.0000155361.83990.5b

Thabet, M. M., and Huizinga, T. W. (2006). Drug evaluation: apratastat, a novel TACE/MMP inhibitor for rheumatoid arthritis. Curr. Opin. Invest. Drugs 7, 1014-1019.

Thoms, B. L., Dudek, K. A., Lafont, J. E., and Murphy, C. L. (2013). Hypoxia promotes the production and inhibits the destruction of human articular cartilage. Arthritis Rheum. 65, 1302-1312. doi: 10.1002/art.37867

Thornton, R. D., Lane, P., Borghaei, R. C., Pease, E. A., Caro, J., and Mochan, E. (2000). Interleukin 1 induces hypoxia-inducible factor 1 in human gingival and synovial fibroblasts. Biochem. J. 350(Pt 1), 307-3012. doi: 10.1042/bj35 00307

Villalvilla, A., Gomez, R., Roman-Blas, J. A., Largo, R., and Herrero-Beaumont, G. (2014). SDF-1 signaling: a promising target in rheumatic diseases. Expert Opin. Ther. Targets 18, 1077-1087. doi: 10.1517/14728222.2014.930440

Wang, Y., Saad, M., Pakunlu, R. I., Khandare, J. J., Garbuzenko, O. B., Vetcher, A. A., et al. (2008). Nonviral nanoscale-based delivery of antisense oligonucleotides targeted to hypoxia-inducible factor 1 alpha enhances the efficacy of chemotherapy in drug-resistant tumor. Clin. Cancer Res. 14, 3607-3616. doi: 10.1158/1078-0432.CCR-07-2020

Westra, J., Brouwer, E., van Roosmalen, I. A., Doornbos-van der Meer, B., van Leeuwen, M. A., Posthumus, M. D., et al. (2010). Expression and regulation of HIF-1alpha in macrophages under inflammatory conditions; significant reduction of VEGF by CaMKII inhibitor. BMC Musculoskelet. Disord. 11:61. doi: 10.1186/1471-2474-11-61

Wigerup, C., Påhlman, S., and Bexell, D. (2016). Therapeutic targeting of hypoxia and hypoxia-inducible factors in cancer. Pharmacol. Ther. doi: 10.1016/j.pharmthera.2016.04.009. [Epub ahead of print].

Williams, R. O., Feldmann, M., and Maini, R. N. (2000). Cartilage destruction and bone erosion in arthritis: the role of tumour necrosis factor alpha. Ann. Rheum. Dis. 59(Suppl. 1), i75-i80. doi: 10.1136/ard.59.suppl_1.i75 
Xu, D., Jiang, H. R., Kewin, P., Li, Y., Mu, R., Fraser, A. R., et al. (2008). IL-33 exacerbates antigen-induced arthritis by activating mast cells. Proc. Natl. Acad. Sci. U.S.A. 105, 10913-10918. doi: 10.1073/pnas.0801898105

Xu, L., Feng, X., Tan, W., Gu, W., Guo, D., Zhang, M., et al. (2013). IL-29 enhances Toll-like receptor-mediated IL- 6 and IL- 8 production by the synovial fibroblasts from rheumatoid arthritis patients. Arthritis Res. Ther. 15, R170. doi: 10.1186/ar4357

Zhang, F.-J., Luo, W., and Lei, G.-H. (2015). Role of HIF-1 $\alpha$ and HIF- $2 \alpha$ in osteoarthritis. Joint Bone Spine 82, 144-147. doi: 10.1016/j.jbspin.2014. 10.003
Conflict of Interest Statement: The authors declare that the research was conducted in the absence of any commercial or financial relationships that could be construed as a potential conflict of interest.

Copyright (C) 2016 Hua and Dias. This is an open-access article distributed under the terms of the Creative Commons Attribution License (CC BY). The use, distribution or reproduction in other forums is permitted, provided the original author(s) or licensor are credited and that the original publication in this journal is cited, in accordance with accepted academic practice. No use, distribution or reproduction is permitted which does not comply with these terms. 